\title{
Hospital staff experiences of their relationships with adults who self-harm: A meta-synthesis
}

\author{
Sophie O’Connor ${ }^{1 *}$, and Lesley Glover ${ }^{2}$ \\ ${ }^{1}$ Department of Psychological Health and Wellbeing, University of Hull, UK \\ ${ }^{2}$ Department of Psychological Health and Wellbeing, University of Hull, UK
}

Word Count (excluding abstract, figures, tables and references): 5964

*Correspondence should be addressed to Sophie O'Connor, Department of Psychological Health and Wellbeing, Aire Building, University of Hull, Cottingham Road, Hull, HU6 7RX, UK (email: sophie.oconnor@outlook.com).

This is the peer reviewed version of the following article: O'Connor, S. and Glover, L. (2017), Hospital staff experiences of their relationships with adults who self-harm: A metasynthesis. Psychol Psychother Theory Res Pract, 90: 480-501. doi:10.1111/papt.12113, which has been published in final form at http://dx.doi.org/10.1111/papt.12113. This article may be used for non-commercial purposes in accordance With Wiley Terms and Conditions for self-archiving.

\section{Abstract}


Purpose. This review aimed to synthesize qualitative literature exploring inpatient hospital staff experiences of their relationships with people who self-harm.

Methods. Nine studies were identified from a systematic search of five research databases. Papers included the experiences of physical health and mental health staff working in inpatient settings. The studies employed various qualitative research methods and were appraised using an adapted quality assessment tool (Tong, Sainsbury, \& Craig, 2007). A meta-synthesis was conducted using traditional qualitative analysis methods including coding and categorizing data into themes.

Results. Three main themes derived from the data. 'The impact of the system' influenced the extent to which staff were 'Fearing the harm from self-harm', or were 'Working alongside the whole person'. A fear-based relationship occurred across mental health and physical health settings despite differences in training; however, 'Working alongside the whole person' primarily emerged from mental health staff experiences. Systemic factors provided either an inhibitory or facilitative influence on the relational process.

Conclusions. Staff experiences of their relationship with people who self-harm were highlighted to have an important impact on the delivery and outcome of care. Increasing support for staff with a focus on distress tolerance, managing relational issues, and developing self-awareness within the relationship may lead to a more mutually beneficial experience of care. Equally, structure, clarity, and support within inpatient systems may empower staff to feel more confident in utilizing their existing skills.

\section{Practitioner points}

- Working with people who self-harm can be emotionally challenging and how staff cope with this can significantly impact on the engagement of staff and patients.

- Increasing the skills of staff in managing relational issues and tolerating distress, as well as providing support and reflective practice groups may be useful in managing emotional responses to working with people who self-harm.

- Refining the supportive, procedural, and environmental structures surrounding the caregiving relationship may help enable better integration of physical and mental health care. 
Health care is under scrutiny as the demand for inpatient services increases, with reports of long waiting times in underfunded and under-resourced departments (Kings Fund, 2015). The increasing demands on hospital services have left staff reporting difficult working conditions and low morale, which is likely to be impacting on patient care (Kings Fund, 2014). The majority report positive experiences of hospital care (Care Quality Commission [CQC], 2015); however, people who present with mental health problems tend to require more support from staff and often have difficult experiences of care (CQC, 2014).

Self-harm was one of the top three reasons for attendance to accident and emergency (A\&E) over 2012/2013; presentations to A\&E following self-harm are increasing (Health\& Social Care Information Centre [H\&SCIC], 2014), and significant proportions of people who present following self-harm attend on more than one occasion (H\&SCIC, 2013; Vedsted, Fink, Sorensen, \& Olesen, 2004). Re-attendance can be costly and places more demand on services that are limited in their ability to go beyond physical health care, potentially impacting on the extent and quality of care that people who self-harm receive (Eastwick \& Grant, 2004; Saunders, Hawton, Fortune, \& Farrell, 2012).

The difficult experiences that people who self-harm report include receiving punitive responses, such as judgemental comments, and having treatment withheld (National Institute of Health and Clinical Excellence [NICE], 2004; Taylor, Hawton, Fortune, \& Kapur, 2009). Despite increased awareness and education, negative attitudes towards people who self-harm appear to have remained consistent across countries and over time (Saunders et al. , 2012).

The attitudes of hospital staff often parallel those of people who self-harm; both describe feelings of frustration and powerlessness (Karman, Kool, Poslawsky, \& van Meijel, 2015; Rees, Rapport, Thomas, John, \& Snooks, 2014; Taylor et al. , 2009). Improving staff responses through training around self-harm is frequently recommended. Unfortunately, the content and quality of such training can vary significantly, and there is little research on the long-term benefits of this training. Furthermore, although training claims to change negative attitudes, a change in attitude does not necessarily reflect behaviour change (Smith \& Louis, 2009).

The staff/patient relationship is argued to positively contribute to outcome and forms an important part of a person's experience of care (Kelley, Kraft-Todd, Schapira, Kossowsky, \& Riess, 2014). A person's initial contact with hospital staff can play a major role in their perceptions of services and care which is likely to influence their subsequent recovery. It has been highlighted that people who present with self-harm can evoke negative responses from health care staff (Huband \& Tantam, 2000). It remains unclear as to what it is about this interaction that may lead to and maintain staff responses, and how this may impact on engagement and recovery. Exploring the interaction between staff and patients is recognized as valuable in improving experiences of care (Department of Health, 2003; Taylor, Marshall, Mann, \& Goldberg, 2012).

Previous reviews have highlighted the demographic and contextual factors that can contribute to negative attitudes (Karman et al. , 2015; Rees et al. , 2014; Saunders et al. , 2012). By synthesizing hospital staff perceptions of their interactions with people who self-harm, further insights may be gained into the process of the relationship and how this may lead to certain experiences. The present review aimed to explore how staff responses may impact on and maintain current care practices for people who self-harm. For the purposes of this review, 
people who self-harm may be referred to as a 'patient' in line with the traditional experience of physical health hospital care.

\section{Method}

\section{Search strategy}

A search of the literature was carried out through the following: CINAHL Complete, Medline, PsycINFO, Web of Science, and Scopus due to their collective breadth and depth of research. The terms 'self harm' OR 'self injur*' OR 'self poison*' OR overdose were entered to include articles that conceptualized self-harm as any act of harm to the self without suicidal intent. The perceived intent of self-harm is suggested to influence the attitudes of staff (Lilley et al., 2008), and the functions of suicidal acts can differ from that of self-harm and need separate responses (Gratz, 2003). For this reason, papers that referred to self-harm as 'parasuicide' or 'suicidal behaviour' were excluded as not to confuse the phenomenon under study.

The following terms were used to identify inpatient staff perceptions of their relationship with patients: staff OR nurse OR doctor or clinic*; A\&E OR 'accident and emergency' OR casualty OR 'emergency department' OR inpatient* OR hospital OR medic*; relationship OR attitude* OR belief* OR view* OR perception* OR experience OR understanding. No limiters were applied. The search was completed in February 2015.

Titles and abstracts were searched to identify relevant articles related to the research aims. Relevant papers were then read to further identify their concordance with the inclusion and exclusion criteria. Papers were included if they used qualitative methodology, and were studies of the experiences of inpatient staff working with adults who self-harm. Papers were included regardless of year of publication or country of origin. Studies were excluded if: they were studies of specific populations or settings (e.g., forensic settings, people with learning disabilities); they were intervention or vignette based research; or they were systematic review papers.

Lastly, papers were 'hand-sourced' through examining the references of included papers to identify any further relevant studies (see Figure 1 for the article selection process). 


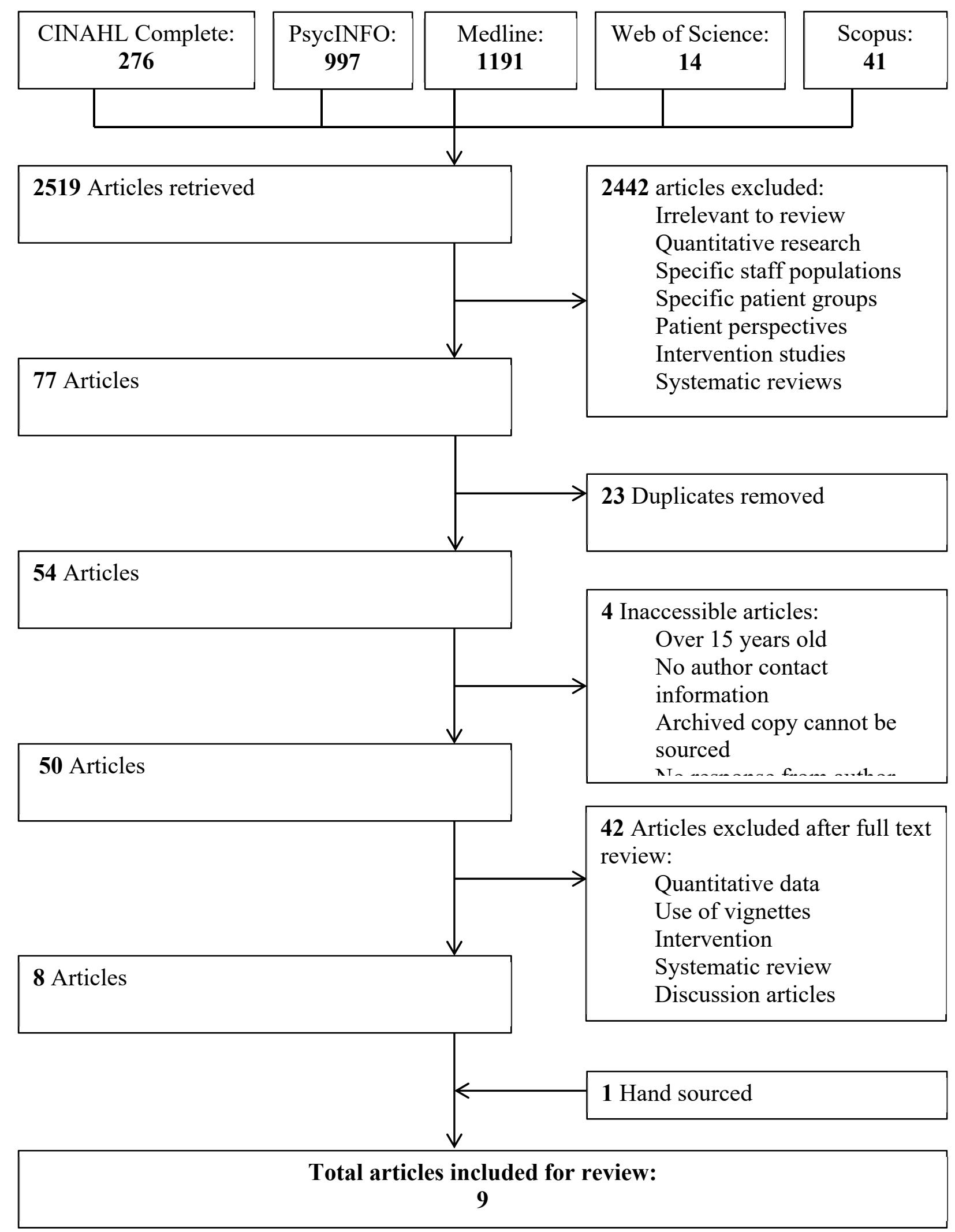

Figure 1. Article selection process. 


\section{Quality assessment}

Quality was assessed using an adapted version of the consolidated criteria for reporting qualitative research (CORE-Q; Tong et al., 2007). The CORE-Q was designed to evaluate qualitative research by assessing the transparency of methods and analyses, and was selected due to its established use. The CORE-Q was refined for the purposes of this review; items evaluating the context of methods, analysis, and interpretation, as well as the reflexive and epistemological perspectives were prioritized. The scoring was also refined for ease of establishing rater reliability. Sandelowski and Barroso (2003) present the argument that quality is subjective; therefore, the exclusion of papers on the basis of perceived quality should be minimized.

All included papers were read by an independent reviewer who rated the full paper. Initially, there was $76.7 \%$ agreement between the first researcher and the independent rater. This rose to $91.0 \%$ agreement following discussion of discrepant cases. The presence of a 'somewhat' option, as well as subjective items on the checklist led to discrepant scores, particularly the questions 'Is context provided to enhance the meaning of the quotes?' and 'Is there a description of diverse cases or minor themes?' Higher agreement on quality was reached after discussing scoring thresholds; evidence was then found for and against the item. Ratings were used to contextualize the included studies, rather than produce absolute judgements of quality.

The papers included in the review varied in methods and in quality. Chapman and Martin (2014), O'Donovan and Gijbels (2006), and Mattson and Binder (2012) scored low in quality due to ambiguity around methodology, analysis, epistemology, and reflexivity. The research by Artis, Smith, and Scarff (2012) was a doctoral thesis which provided context around the research and methods and as a result was rated higher, along with Tofthagen, Talseth, and Fagerstrom (2014). Both of these papers were directed by specific theory or aims; however, transparency allowed for an awareness of the impact on the analysis and interpretation.

\section{Meta-synthesis}

Meta-syntheses aim to integrate qualitative research of various methodological and epistemological orientations to develop further understanding surrounding a phenomenon (Paterson, Thorne, Canam, \& Jillings, 2001; Paterson et al., 2009; Walsh \& Down, 2005). By synthesizing and interpreting pre-existing literature, it may be possible to go beyond the current 'truth' of staff experiences of working with people who self-harm and begin to explore why certain interactions may occur.

The methods of meta-synthesis remain somewhat ambiguous in terms of a prescriptive procedure. The analysis for the present review reflected that of first-hand qualitative research and was undertaken by the first author. The full 'results' section from each paper was extracted on to a separate document. Linguistic, descriptive, and conceptual aspects were noted in the margins, which were later reviewed to establish salient, common, or contrasting features for the development of codes. Codes were labelled using the language of the data as far as possible and were tabulated with the corresponding data. The identified codes within each paper were mapped out and cross-referenced to identify common or contrasting phenomena and categorized accordingly. Once themes within a paper were identified, these were then 
compared and contrasted between papers, as described by Noblit and Hare (1989), to form suband superordinate themes, reflecting salient features in staff experiences. The codes and themes were discussed with the second author at each stage of development.

This review included papers using thematic and content analysis, ethnography, and interpretive phenomenological analysis. It was assumed that 'true' experience is inaccessible; cultural, social, and personal experience shapes perceptions; however, meaning can be cocreated through interaction. The first author had experience, both as a volunteer and as a clinician, of working with people who self-harm and was also completing qualitative research investigating the experiences of people who self-harm alongside the present review. The influence of these experiences on the analysis and interpretation of the review were explored through reflective journaling, discussions with the second author, and through participation in a qualitative peer group.

\section{Findings}

In total, nine international papers were included for review. Four papers explored MH staff perceptions: Wilstrand, Lindgren, Gilje, and Olofsson (Sweden; 2007); O’Donovan and Gijbels (Ireland; 2006); Mattson and Binder (Norway; 2012); and Tofthagen et al. (Norway; 2014). Five papers investigated the perceptions of PH hospital staff: Artis et al. (United Kingdom; 2012); Hopkins (United Kingdom; 2002); Hadfield, Brown, Pembroke, and Hayward (United Kingdom; 2009); Chapman and Martin (Australia; 2014); and Senarathna, Adams, De Silva, Buckley, and Dawson (Sri Lanka; 2008). The main characteristics of the included studies are located in Table 1.

The cultural, environmental, and demographic factors for staff in their experiences of working with people who self-harm varied, as did the theoretical approaches employed, and inclusion of staff members. It is interesting to note that the $\mathrm{MH}$ studies were primarily based in Sweden and Norway, and the PH studies were mainly UK-based. Three main themes emerged from staff experiences of working with people who self-harm. 'The impact of the system' influenced the extent to which staff were 'fearing the harm from self-harm' or were 'working alongside the whole person'. Figure 2 outlines the interaction between the themes. 
Table 1. Characteristics of included studies with quality rating scores

\begin{tabular}{|c|c|c|c|c|c|c|c|}
\hline $\begin{array}{l}\text { Author } \\
\text { (year) } \\
\text { Country }\end{array}$ & Aims & Sampling & $n$ & Participant characteristics & Data collection & $\begin{array}{c}\text { Methodological and } \\
\text { theoretical } \\
\text { orientation }\end{array}$ & $\begin{array}{c}\text { Quality } \\
(\%)\end{array}$ \\
\hline $\begin{array}{l}\text { Artis, et al. } \\
(2012) \\
\text { United } \\
\text { Kingdom }\end{array}$ & $\begin{array}{l}\text { To explore } \\
\text { staff attitudes } \\
\text { and } \\
\text { behaviours, } \\
\text { and the impact } \\
\text { on effective } \\
\text { treatment, team } \\
\text { identification, } \\
\text { and norms }\end{array}$ & $\begin{array}{l}\text { Voluntary } \\
\text { sample }\end{array}$ & 10 & $\begin{array}{l}\text { Three male and seven } \\
\text { female participants; } \\
\text { Two doctors, one manager, } \\
\text { four senior nurses, two } \\
\text { staff nurses, and one } \\
\text { healthcare assistant }\end{array}$ & $\begin{array}{l}\text { Semi-structured } \\
\text { interviews lasting } \\
\text { between } 20 \text { to } 60 \\
\text { minutes conducted } \\
\text { at A\&E }\end{array}$ & $\begin{array}{l}\text { Thematic Analysis; } \\
\text { Theory of group } \\
\text { norms and identity }\end{array}$ & 59.7 \\
\hline $\begin{array}{l}\text { Chapman } \\
\text { and Martin } \\
\text { (2014) } \\
\text { Australia }\end{array}$ & $\begin{array}{l}\text { To explore } \\
\text { staff } \\
\text { perceptions of } \\
\text { caring for } \\
\text { people who } \\
\text { present to the } \\
\text { emergency } \\
\text { department } \\
\text { following self- } \\
\text { poisoning }\end{array}$ & $\begin{array}{l}\text { Voluntary } \\
\text { sample } \\
\text { recruited } \\
\text { from } 3 \\
\text { Emergency } \\
\text { Departments }\end{array}$ & 169 & $\begin{array}{l}45 \% \text { of staff participated: } \\
\text { Nurses: } \mathrm{n}=133 ; 11 \text { males; } \\
122 \text { females; mean age= } \\
33 \text { years; mean length of } \\
\text { experience in the } \\
\text { Emergency Department = } \\
4.7 \text { years } \\
\text { Doctors: } \mathrm{n}=53 ; 35 \text { males; } \\
18 \text { females; mean age }= \\
39 \text { years; mean length of } \\
\text { experience in the } \\
\text { Emergency Department }= \\
9 \text { years }\end{array}$ & $\begin{array}{l}\text { The Attitudes } \\
\text { towards Deliberate } \\
\text { Self-Harm } \\
\text { Questionnaire } \\
\text { (McAllister, Creedy, } \\
\text { Moyle, \& Farrugia, } \\
\text { 2002); included staff } \\
\text { were those whom } \\
\text { responded to the } 2 \\
\text { open-ended } \\
\text { questions }\end{array}$ & $\begin{array}{l}\text { No specific method } \\
\text { stated. Reported to } \\
\text { use qualitative data } \\
\text { analysis of coding, } \\
\text { categorising and } \\
\text { clustering. } \\
\text { (One of two papers; } \\
\text { see Martin \& } \\
\text { Chapman, 2014) }\end{array}$ & 46.8 \\
\hline
\end{tabular}


Table 1. (continued)

\begin{tabular}{|c|c|c|c|c|c|c|c|}
\hline $\begin{array}{l}\text { Hadfield, } \\
\text { et al. } \\
(2009) \\
\text { United } \\
\text { Kingdom }\end{array}$ & $\begin{array}{l}\text { To explore the } \\
\text { meaning that } \\
\text { A\&E doctors } \\
\text { attribute to } \\
\text { experiences of } \\
\text { treating people } \\
\text { who self-harm, } \\
\text { and how this } \\
\text { relates to the } \\
\text { treatment } \\
\text { offered }\end{array}$ & $\begin{array}{l}\text { Purposive } \\
\text { sample } \\
\text { recruited } \\
\text { from } 2 \text { A\&E } \\
\text { departments }\end{array}$ & 5 & $\begin{array}{l}\text { Three female and two male } \\
\text { A\&E doctors. Mean length } \\
\text { of experience of treating } \\
\text { people who self-harm was } \\
7.1 \text { years }\end{array}$ & $\begin{array}{l}\text { Interviews were } \\
\text { audio recorded and } \\
\text { lasted between } 40 \text { to } \\
75 \text { minutes }\end{array}$ & IPA & 58.9 \\
\hline $\begin{array}{l}\text { Hopkins } \\
(2002) \\
\text { United } \\
\text { Kingdom }\end{array}$ & $\begin{array}{l}\text { To gain an } \\
\text { understanding } \\
\text { of what it } \\
\text { means to } \\
\text { nurses on } \\
\text { medical } \\
\text { admissions } \\
\text { units to have } \\
\text { patients who } \\
\text { self-harm }\end{array}$ & $\begin{array}{l}\text { Purposive } \\
\text { sample }\end{array}$ & 4 & $\begin{array}{l}\text { Four general nurses } \\
\text { working in } 2 \text { Medical } \\
\text { Admissions Units }\end{array}$ & $\begin{array}{l}\text { Observations, field } \\
\text { notes and semi- } \\
\text { structured } \\
\text { interviews. } \\
\text { Interviews were } \\
\text { audio recorded and } \\
\text { lasted between } 30 \text { to } \\
60 \text { minutes }\end{array}$ & Ethnography & 57.3 \\
\hline
\end{tabular}

Continued 
Table 1. (continued)

\begin{tabular}{|c|c|c|c|c|c|c|c|}
\hline $\begin{array}{l}\text { Mattson } \\
\text { and Binder } \\
(2012) \\
\text { Norway }\end{array}$ & $\begin{array}{l}\text { To explore } \\
\text { how healthcare } \\
\text { workers think, } \\
\text { feel and act } \\
\text { when working } \\
\text { with patients } \\
\text { who self-harm }\end{array}$ & $\begin{array}{l}\text { Sample } \\
\text { recruited } \\
\text { from a } \\
\text { psychiatric } \\
\text { ward }\end{array}$ & 8 & $\begin{array}{l}\text { Three nurses, two 'licenced } \\
\text { practical nurses', two } \\
\text { 'social educators', and one } \\
\text { Clinical Psychologist } \\
\text { (Mattson \& Binder, 2012, } \\
\text { p. 274) }\end{array}$ & $\begin{array}{l}\text { Semi-structured } \\
\text { interviews were } \\
\text { audio-recorded and } \\
\text { conducted at the } \\
\text { psychiatric ward. } \\
\text { Interviews lasted on } \\
\text { average for } 45 \\
\text { minutes. } \\
\text { The ward had } \\
\text { experienced a } \\
\text { reduction in self- } \\
\text { harm; interviews } \\
\text { focused on past } \\
\text { experience and } \\
\text { difference over time }\end{array}$ & IPA & 46.8 \\
\hline $\begin{array}{l}\text { O’Donova } \\
\mathrm{n} \text { and } \\
\text { Gijbels } \\
\text { (2006) } \\
\text { Ireland }\end{array}$ & $\begin{array}{l}\text { To gain an } \\
\text { understanding } \\
\text { of the practices } \\
\text { of nurses } \\
\text { working with } \\
\text { people whom } \\
\text { self-harm } \\
\text { without } \\
\text { suicidal intent }\end{array}$ & $\begin{array}{l}\text { Convenience } \\
\text { sample } \\
\text { recruited } \\
\text { from } 2 \\
\text { psychiatric } \\
\text { admissions } \\
\text { units }\end{array}$ & 8 & $\begin{array}{l}\text { Six female and three male } \\
\text { psychiatric nurses aged } \\
\text { between } 25 \text { to } 55 \text { years old. } \\
\text { Length of experience in } \\
\text { psychiatric units ranged } \\
\text { from } 6 \text { months to } 15 \text { years }\end{array}$ & $\begin{array}{l}\text { Semi-structured } \\
\text { interviews }\end{array}$ & $\begin{array}{l}\text { Content Analysis } \\
\text { and thematic } \\
\text { analysis } \\
\text { (One of } 2 \text { papers; } \\
\text { see O'Donovan, } \\
\text { 2007) }\end{array}$ & 42.7 \\
\hline
\end{tabular}

Continued 
Table 1. (continued)

\begin{tabular}{|c|c|c|c|c|c|c|c|}
\hline $\begin{array}{l}\text { Senarathna } \\
\text {, et al. } \\
\text { (2008) } \\
\text { Sri Lanka }\end{array}$ & $\begin{array}{l}\text { To explore the } \\
\text { experiences } \\
\text { and perceptions } \\
\text { of primary care } \\
\text { doctors in rural } \\
\text { Sri Lanka } \\
\text { towards the } \\
\text { treatment of } \\
\text { people who } \\
\text { self-harm }\end{array}$ & $\begin{array}{l}\text { Voluntary } \\
\text { sample } \\
\text { recruited } \\
\text { from } 13 \\
\text { hospitals } \\
\text { with } \\
\text { inpatient } \\
\text { facilities }\end{array}$ & 15 & $\begin{array}{l}\text { Thirteen male and two } \\
\text { female doctors recruited; } \\
10 \text { were in the age range of } \\
35 \text { to } 40 \text { years; length of } \\
\text { experience range }=1 \text { to } 8 \\
\text { years. Thirteen participants } \\
\text { had more than } 2 \text { years' } \\
\text { experience. Thirteen } \\
\text { doctors consented but did } \\
\text { not participate }\end{array}$ & $\begin{array}{l}\text { Semi-structured } \\
\text { interviews were } \\
\text { conducted in } \\
\text { Sinhalese and } \\
\text { independently } \\
\text { translated in to } \\
\text { English. Interviews } \\
\text { lasted between } 20 \text { to } \\
30 \text { minutes and were } \\
\text { recorded }\end{array}$ & Thematic analysis & 55.6 \\
\hline $\begin{array}{l}\text { Tofthagen } \\
\text { et al. } \\
\text { (2014) } \\
\text { Norway }\end{array}$ & $\begin{array}{l}\text { To explore } \\
\text { mental health } \\
\text { nurses' } \\
\text { experiences of } \\
\text { caring for } \\
\text { inpatients who } \\
\text { self-harm }\end{array}$ & $\begin{array}{l}\text { Purposive } \\
\text { sample } \\
\text { recruited } \\
\text { through } \\
\text { nursing } \\
\text { managers }\end{array}$ & 15 & $\begin{array}{l}\text { Thirteen female and two } \\
\text { male participants working } \\
\text { across four psychiatric } \\
\text { clinics; } 12 \text { mental health } \\
\text { nurses; } 3 \text { general nurses } \\
\text { with mental health } \\
\text { experience; length of } \\
\text { experience in psychiatric } \\
\text { hospitals ranged from } 1 \text { to } \\
14 \text { years ( } \mathrm{m}=5.1 \text { years) }\end{array}$ & $\begin{array}{l}\text { Semi-structured } \\
\text { interviews lasting } \\
\text { between } 45 \text { to } 90 \\
\text { minutes; audio- } \\
\text { recorded }\end{array}$ & $\begin{array}{l}\text { Content analysis } \\
\text { The study is within } \\
\text { the context of the } \\
\text { Tidal Model and a } \\
\text { 'person-centred } \\
\text { approach' }\end{array}$ & 60.5 \\
\hline $\begin{array}{l}\text { Wilstrand, } \\
\text { et al. } \\
(2007) \\
\text { Sweden }\end{array}$ & $\begin{array}{l}\text { To gather } \\
\text { nurses' } \\
\text { descriptions of } \\
\text { their } \\
\text { experiences of } \\
\text { caring for } \\
\text { patients who } \\
\text { self-harm }\end{array}$ & $\begin{array}{l}\text { Purposive } \\
\text { sample } \\
\text { recruited by } \\
\text { the nurse } \\
\text { manager }\end{array}$ & 6 & $\begin{array}{l}\text { Three male and two female } \\
\text { nurses working in } 4 \\
\text { psychiatric units; } 2 \text { general } \\
\text { nurses, and } 4 \text { psychiatric } \\
\text { nurses with one trained in } \\
\text { psychotherapy. Participants } \\
\text { were aged between } 27 \text { and } \\
53 \text { years }(\mathrm{m}=40) \text {. Length of } \\
\text { experience ranged from } 1 \\
\text { to } 18 \text { years }(\mathrm{m}=9.4)\end{array}$ & $\begin{array}{l}\text { Narrative interviews } \\
\text { conducted and } \\
\text { audiotaped at } \\
\text { psychiatric clinics. } \\
\text { Interviews lasted } \\
\text { between } 40 \text { to } 50 \\
\text { minutes }\end{array}$ & Content analysis & 58.9 \\
\hline
\end{tabular}




\section{Fearing the harm from self-harm}

Desperately trying to prevent harm but not knowing what to do

People who self-harm can present significant risks to their health. Uncontained feelings of fear and anxiety lead staff to become preoccupied with managing patients' risk and the subsequent emotional impact on themselves.

"She nearly succeeded in taking her life, the fear we felt. . It's unfair to expose another person to that; it is very hard to think about" (Wilstrand et al., 2007, p. 75)

Strong uncertainty surrounded staff ability to assess a patient's level of risk, understand the functions of self-harm, and how to respond in incidents where harm had occurred (Artis et al., 2012; Chapman \& Martin, 2014; O’Donovan \& Gijbels, 2006; Senarathna et al., 2008). Approaches to self-harm were inconsistent and ambiguous; staff perceived patients to be too different to establish consistent methods of managing self-harm and its risks (Artis et al., 2012; Chapman \& Martin, 2014; O’Donovan \& Gijbels, 2006).

Both $\mathrm{MH}$ and $\mathrm{PH}$ staff described being hyper-vigilant, and developing a 'sixth sense' to the risks that a patient may present (Hopkins, 2002; Tofthagen et al., 2014; Wilstrand et al., 2007). Understanding of the functions of the self-harm linked to perceived levels of risk; patients deemed 'manipulative' or 'attention seeking' (Hadfield et al., 2009; Hopkins, 2002; Wilstrand et al., 2007) were seen to pose less of a risk and evoked feelings of anger and frustration. It was believed that 'manipulative' behaviour should not be 'rewarded' (Hadfield et al. , 2009; Mattson \& Binder, 2012; Wilstrand et al. , 2007) leading to acts of self-harm being ignored or avoided.

The emotional impact of working with people who self-harm was more explicitly discussed in Hadfield et al. (2009). Staff fears included losing their own sanity and being unable to contain their strong emotional responses.

"I guess in some senses it's for your own sanity as well because you don't want to hear you know every day someone's awful, awful life, life story. . . So I suppose in some ways it is some kind of self-preservation" (Hadfield et al., 2009, p. 761) 


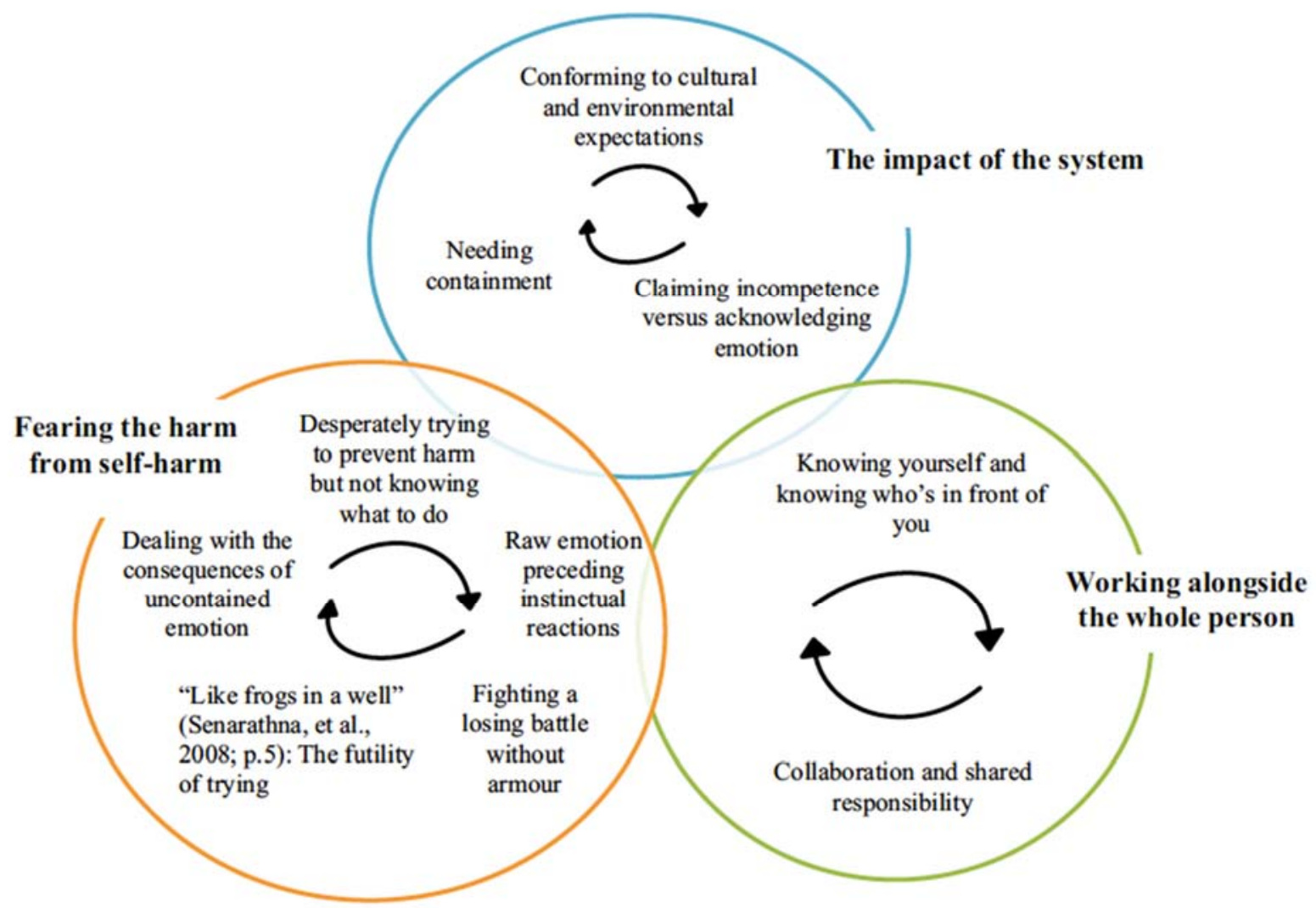

Figure 2. A graphic displaying the interactions between the superordinate and subordinate themes.

\section{Raw emotion preceding instinctual reactions}

At times of uncertainty, fear, and perceived high risk, staff tended to act on an impulse:

"I think you can be a little too easy with this, actually that you too quickly give medication when we notice that we are unsure." (Tofthagen et al., 2014, p. 6)

The instinct to minimize harm took over. Both $\mathrm{MH}$ and $\mathrm{PH}$ staff experienced an overwhelming sense of responsibility; patients were perceived to be vulnerable and incapable of taking an active part in their care (Hadfield et al., 2009; Hopkins, 2002; Tofthagen et al., 2014).

“... Because of their mental health problems they don't have the insight to make a rational decision some of the time. . we've got to do it for them." (Hadfield et al., 2009, p. 760)

The anxiety from holding full responsibility for patient welfare resulted in restrictive and coercive responses to risk, including close observation, isolation, withdrawal of leave and 
possessions, medication, and restraint (Mattson \& Binder, 2012; O'Donovan \& Gijbels, 2006; Tofthagen et al., 2014).

". . . Before, if someone had a razor that they could [use to] hurt themselves. . . You were completely hysterical about what they might do. . . You were going to get it [the razor] at any cost." (Mattson \& Binder, 2012, p. 277)

\section{Fighting a losing battle without armour}

Despite attempts at preventing risk, staff inevitably found that taking control was not sustainable; patients sought new methods of self-harm, or presented challenges to staff interventions (Mattson \& Binder, 2012; Tofthagen et al., 2014 Wilstrand et al., 2007). The methods intended to protect actually resulted in adverse effects on the relationship and engagement.

Taking control to minimize risk could result in an escalation of patients' behaviours. PH staff reported the prevalence of violence and aggression from patients (Chapman \& Martin, 2014; Hopkins, 2002). This was accompanied by a sense that staff welfare was not a priority for their employer, leaving staff feeling vulnerable and exposed (Artis et al., 2012; Hadfield et al., 2009; O’Donovan \& Gijbels, 2006; Wilstrand et al., 2007).

"I think you just have to [manage]. . So to have that protocol there ensures the patient's safety really, more than ours. .." (Hadfield et al., 2009, p. 761)

'Like frogs in a well' (Senarathna et al. , 2008, p. 5): The futility of trying

Attempts at managing risk for both $\mathrm{MH}$ and $\mathrm{PH}$ staff were often unsuccessful. Patients' repeated self-harm led staff to experience a sense of defeat and inadequacy (Artis et al., 2012; Chapman \& Martin, 2014; Hadfield et al., 2009; Hopkins, 2002; Senarathna et al., 2008; Wilstrand et al., 2007). This was associated with a decrease in empathy and engagement with patients (Chapman \& Martin, 2014; Hadfield et al., 2009; Hopkins, 2002). Feelings of inadequacy were more apparent for PH staff, whose orientation with the medical model led to a need to see more immediate change (Artis et al., 2012; Chapman \& Martin, 2014; Hadfield et al., 2009; Hopkins, 2002). Attempts to help patients were experienced as hopeless; interventions were carried out 'time and time again' (Hopkins, 2002, p. 151).

"I feel like I'm not doing my job properly, because my job is to help people and I can't help them." (Artis et al., 2012, p. 44)

\section{Dealing with the consequences of uncontained emotion}

As efforts to protect the patient and manage risk were unsuccessful, staff resorted to defend themselves. Physical health staff attributed challenges in patient care as the responsibility of society, mental health services, and the individual (Artis et al., 2012; Hadfield et al., 2009; 
Senarathna et al., 2008) in preventing change. Staff responses depended on factors including perceived lethality and severity of self-harm. This provided a sense of justification for their own behaviour and patient outcome, reducing feelings of inadequacy (Chapman \& Martin, 2014; Hadfield et al., 2009; Hopkins, 2002; Senarathna et al., 2008). In most cases, the perception that self-harm was a reaction to social or situational circumstances led staff to respond to more empathy than when self-harm was perceived to be related to mental health problems.

"I feel for someone who has felt overwhelmed by a situation and maybe self-poisoned on an impulse, which they either regret after doing so, or remain feeling so hopeless and depressed that they still wish to die. I feel exasperated and annoyed with a patient if I perceive them to

have self-poisoned (especially if it was to a minor degree) then notified someone to help them." (Chapman \& Martin, 2014, p. 141)

Avoidance was the most dominant coping strategy for $\mathrm{MH}$ and $\mathrm{PH}$ staff. Physical avoidance of patients, avoiding talking about distress, and emotional distancing were methods used for self-protection (Artis et al. , 2012; Hadfield et al. , 2009; Hopkins, 2002; Tofthagen et al. , 2014; Wilstrand et al. , 2007). If avoidance was not enough, staff engaged in punitive behaviours including humiliating patients, and trivializing or minimizing patient distress.

"The participants noticed staff losing control of their emotions by shouting at the patient, grasping the patient's arm tightly, and humiliating patients.” (Wilstrand et al., 2007, p. 75)

The overwhelming emotional response to managing risk without support or clear procedures led to inconsistency, biased assessments, and displacement of responsibility. Uncontained and unprocessed emotion induced impulsive and punitive responses. Suppressing strong emotions of anger and fear maintained a need to avoid patient distress; however, this was unsustainable, impacting adversely on the caregiving relationships, contributing to the maintenance of a sense of hopelessness and escalating risk.

\section{Working alongside the whole person}

Knowing yourself and knowing who is in front of you

Managing the relationship with people who self-harm in a way which held hope was more apparent in experiences of MH staff in research completed outside of the United Kingdom.

". . To persevere and withstand the relationship and bear hope regarding the patient's recovery when the patient him/herself is unable to envision such occurring" (Tofthagen et al., 2014, p. 4)

Understanding, acknowledging, and identifying the role of self-harm for a patient, and the intention behind the behaviour provided staff with an ability to know the person. This 
allowed staff to more effectively tolerate risk leading to more appropriate responses (Mattson \& Binder, 2012; O’Donovan \& Gijbels, 2006; Tofthagen et al., 2014).

Reflection upon their own contribution to the caregiving relationship encouraged selfawareness and understanding of when they may contribute to the maintenance of distress. Understanding their own contributions allowed staff to separate their feelings from those of the patients and implement clear boundaries. Staff were then able to provide containment and safety in times of distress, ensuring the relationship and associated responses were predictable and certain for patients.

"I am able to separate myself. . . from the patient's feelings. . . to stop this projection storm." (Tofthagen et al., 2014, p. 5)

\section{Collaboration and shared responsibility}

Responding appropriately to patient need consisted of collaboration, acknowledgement, reflection, and communication. Initially, staff built an alliance with the patient based on trust, whereby both parties were jointly responsible for risk management. Collaboration increased motivation and promoted autonomy; staff responses communicated belief in the patient's capability to learn to cope in alternative ways (Hadfield et al., 2009; Mattson \& Binder, 2012; Tofthagen et al., 2014; Wilstrand et al., 2007).

If self-harm could not be prevented, staff acknowledged and attended to the physical injury. Once distress had reduced, staff explored the reasons, feelings, and triggers behind the self-harm, encouraging reflection and awareness. From this, staff supported the patient to problem solve alternative methods to delay the use of self-harm next time (Hadfield et al., 2009; Mattson \& Binder, 2012; O’Donovan \& Gijbels, 2006; Tofthagen et al., 2014; Wilstrand et al., 2007).

"If you only ignore it, you're sending a signal that it doesn't matter to you. They can just keep doing it, hurt themselves as much as they want to, because you don't care . . . It's more comprehensive than just a cry for attention ... there's a lot of pain under there." (Mattson \&

Binder, 2012, p. 279)

What was unique to MH staff was a sense of the bigger picture; recovery was a process that occurs over time as a person gradually learns alternative ways of coping when presented with overwhelming situations (Mattson \& Binder, 2012; Tofthagen et al. , 2014).

Taking the time to develop understanding of emotional responses and the subsequent impact on the caregiving relationship provided a foundation for collaborative working. Understanding enabled the identification of clear boundaries and approaches, leading to shared responsibility and increased tolerance of risk. Realistic expectations of recovery allowed staff to hold hope and belief in patients.

\section{The impact of the system}

Conforming to cultural and environmental expectations 
Fearing self-harm co-occurred with causal attributions of challenges to a lack of time and resources, particularly for $\mathrm{PH}$ staff who encountered dilemmas regarding balancing patient welfare versus systemic demands (Artis et al., 2012; Senarathna et al., 2008).

"In the ED the focus of care is on the emergency not the mental health/counselling. I feel as if I (1) don't have time to explore MH issues, (2) aren't encouraged to explore MH issues, (3) don't feel as though the department is the right place to explore this." (Chapman \& Martin, 2014, p. 143)

People with mental health problems were perceived to be a significant drain on time and resources (Artis et al., 2012; Chapman \& Martin, 2014; Hadfield et al., 2009; Senarathna et al., 2008). Frustrated staff spent time on observations, chasing up mental health teams, or being involved in risk management. The PH staff held the view that wards were not an appropriate place for MH patients (Artis et al., 2012; Chapman \& Martin, 2014; Hadfield et al., 2009; Hopkins, 2002), and superficial interactions resulted from prioritizing systemic rather than patient needs.

"I guess not knowing too much is good ... just don't have the time to be able to do that. .." (Hadfield et al., 2009, p. 761)

\section{Claiming incompetence versus acknowledging emotion}

Despite the differences in training, MH and PH staff felt under-skilled in working with people who self-harm. PH staff reported avoiding patients once they were deemed medically fit as emotional distress was seen to be beyond their remit and competence. The need for more training was mainly described as a solution (Artis et al., 2012; Chapman \& Martin, 2014; Hadfield et al., 2009; Senarathna et al., 2008); however, barriers to feeling confident utilizing the skills were apparent for staff.

". . Even if there were increased resources or training, there would still "not be the time" to implement learning." (Artis et al., 2012, p. 44)

In contrast, some staff acknowledged the impossible nature of meeting all expectations; it was recognized that personal feelings will influence interactions, and therefore, emotional responses need to be addressed (O'Donovan \& Gijbels, 2006). Ideally, both staff and patients should be cared for (Mattson \& Binder, 2012).

\section{Needing containment}

The fear of self-harm was exacerbated in systems where staff felt uncertain, isolated, and exposed. Those engaging in positive interactions described a need for structure, support, and consistency in approach (O'Donovan \& Gijbels, 2006). Clarity of roles and boundaries enabled staff to contain and tolerate the risks of self-harm. 
"To be clear about the rules from the beginning and the whole staff has to be informed and supportive so that we work on the same script." (Wilstrand et al., 2007, p. 75)

Active management was felt to facilitate less restrictive and fearful cultures, allowing understanding and change in the caregiving relationship (Mattson \& Binder, 2012). The need for supervision and debriefing was a valuable outlet for emotion by increasing communication, reflection, and shared experience. These positive systemic influences enabled staff to work more effectively with people who self-harm (Artis et al., 2012; Wilstrand et al., 2007).

Both MH and PH staff encountered similar demands to time and resources. Despite possessing core skills in caring for people, many staff felt unable to utilize them when working with people who self-harm. Attributing responsibility to the system provided cultural justification for avoiding emotional distress. Comparatively, accepting emotional responses provided space for establishing staff and patient needs. The positive influence of systemic factors such as supervision and culture change was best facilitated by active management.

\section{Discussion}

There are a number of factors to keep in mind when drawing conclusions about this review. This synthesis included a small number of research papers, within a limited scope of inpatient settings and countries; the findings will not be applicable to all staff and settings. It is also acknowledged that only staff experiences were reviewed, reflecting one part of an interaction. For the purposes of the present investigation, papers describing constructs such as 'attitudes' have been translated into representations of the relationship which may not always be the case. Additionally, qualitative research and reviews involve a high level of interpretation; the methodology and assessment of quality can be subjective.

\section{The staff-patient relationship}

The review identifies important considerations for improving patient experiences of care. Various studies have highlighted that difficult experiences for patients include punitive and restrictive care. It has also been suggested that negative experiences may be a result of the characteristics of the patient group in how they perceive care (National Institute of Health Research [NIHR], 2008). This review suggests that staff acknowledge unacceptable care and play a significant part in patient's difficult experiences. Staff ability to cope with the relational process is likely to impact on their own perceptions of providing care to people who self-harm. By observing the process of the interaction rather than the 'characteristics' of one part or the other, this can provide a more balanced perspective of the problem rather than attributing fault to one party that can maintain a fear-based interaction.

The theme of 'fearing the harm from self-harm' highlights the emotional demands on staff. Both MH and PH staff described avoiding patients' distress, suggesting that regardless of training or expertise in mental health, managing the emotional impact of the work is an important factor in the relationship. The experiential avoidance model of self-harm (Chapman, Gratz, \& Brown, 2006) suggests that self-harm is a method of avoiding uncomfortable and distressing internal events such as feelings, thoughts, and memories. Avoidance provides some short-term relief, but may lead to increased discomfort in the long term (Chapman et al. , 2006); people distract from the distress and prevent tolerating the discomfort. Experiential avoidance 
was also described in the present review; staff avoided people who self-harm and the associated distress that this interaction brings, such as feelings of failure. When avoidance was no longer sustainable, staff distress was expressed intensely, often towards patients. The level of emotional avoidance by both staff and patients may contribute to the maintenance of self-harm; patients potentially receive the message that their emotion is unmanageable, and neither staff nor patients can learn to tolerate distress.

Chapman et al. (2006) report that emotional avoidance often occurs in individuals who engage in reward-based behaviour and have higher levels of novelty seeking and/or impulsivity. People who work in acute settings may chose the specific field as a result of its changing environment, adrenaline-fuelled role, and ability to make an instant impact (Byrne \& Heyman, 1997). Individuals may also be more likely to respond to more urgency as a result of negative emotion (Chapman et al. , 2006). This was reflected in staff methods of taking control to minimize risk. Bringing these parallel experiences into staff awareness through reflection and supervision could lead to more effective care relationships.

People who self-harm are frequently perceived to be challenging, evoking significant emotional reactions, and often divide staff teams (Huband \& Tantam, 2000). Sheard et al. (2000) suggested that patients' methods of coping can evoke reactions such as avoidance, hostility, or rescuing responses from staff. Sheard et al. (2000) described these responses as collusive interactions with patients' processes that can contribute to the maintenance of selfharm; patients may experience rejection and frustration, increasing their unmanageable feelings and therefore the need to cope through self-harm.

Gratz (2003) suggested that people who self-harm are more likely to have 'insecure' attachment types and that the development of self-harm may be associated with early emotional neglect (Linehan, 1993). The inconsistent and emotionally avoidant caregiving response may be a replication of patient's early relationships. When a relationship is unpredictable and inconsistent, gaining a sense of control provides feelings of safety (Bowlby, 1973; Crittenden, 1999) and for patients this may be in the form of self-harm. Unfortunately, the uncertainty and inconsistency can lead staff to seek control through restrictive practice, which in turn may increase patient's powerlessness and therefore risk. In contrast, the process of 'knowing yourself and knowing who's in front of you' is consistent with building a secure attachment base. Staff identified, acknowledged, and responded appropriately to patients' distress with clear and consistent boundaries. This relationship provided comfort and protection for patients, as well as encouraging emotional development (Adshead, 1998).

\section{The context of the relationship}

Caregiver behaviour can impact on feelings of safety in the care receiver. This may also represent interactions between management and staff; staff who feel unsafe and uncontained in response to management may struggle more to contain their own interactions with patients (Adshead, 1998). Staff in the present review described feeling vulnerable within their system, whereas staff who were able to engage in 'knowing yourself. . ' valued structure, support, and active management (Mattson \& Binder, 2012). The systemic demands as well as the culture of the workplace did not foster compassionate responses; there was little tolerance for emotional expression for staff or patients. Distress tolerance, empathy, and motivation are essential 
factors in the delivery of compassionate care (Cole-King \& Gilbert, 2011) which can be inhibited by high levels of emotion, preoccupation, and a lack of support.

The themes of 'fearing the harm from self-harm' and 'knowing yourself and knowing who's in front of you' pose somewhat opposite approaches to responding to patients that may be reflective of some of the differences between MH and PH staff. Firstly, there are significant differences in the responsibilities and nature of care between $\mathrm{PH}$ and MH staff; patients tend to spend longer in mental health hospitals which often have higher concentrations of people with complex presentations. Physical health environments can have high patient turnovers that can affect the depth of an interaction. For PH staff, the tendency to focus on physical care may be one method of managing the intensity of the work (Hadfield et al., 2009) especially in fastpaced busy environments where support is often limited. In comparison, MH contexts are also demanding, but are more likely to have established support systems and focus on emotional well-being and self-care, possibly allowing MH to seek to develop understanding with patients. Fearful staff described the need to determine the legitimacy of self-harm which depended on the patient's narrative. However, this conflicts with the need to avoid the patient distress, but also the limits of PH environments. The avoidance may lead to assumptions that self-harm is not legitimate due to not enquiring about their story, or staff make assumptions on the basis of second-hand information. Furthermore, this contrasts with 'knowing yourself, and knowing who's in front of you' whereby staff described a need to explore the reasons behind the selfharm and help the patient verbalize their experiences to promote reflection and change. As staff describe difficulties in tolerating patient distress, this may inhibit their ability to support the patient to verbalize their experience, potentially reinforcing the need to communicate distress through self-harm.

\section{Clinical implications}

Both $\mathrm{MH}$ and $\mathrm{PH}$ staff reported having little time for meaningful patient interaction, despite $\mathrm{MH}$ staff having more appropriate resources to do so. Mental health issues were described to be time demanding, which linked to biased assessment of risk and associated management strategies. Investing time to consider the relationship and staff influence upon this promotes an interaction that progressively reduces the demand on resources; patients may experience less of a need to escalate their behaviour to seek care, or communicate through self-harm.

Staff training is a frequent recommendation by research that explores staff attitudes (e.g., Rees et al., 2014). The present synthesis identified that both MH and PH staff experienced the process of 'fearing the harm from self-harm' despite training differences. Huband and Tantam (2000) found significant differences in attitudes towards people who self-harm between those who had received qualifications in therapeutic approaches than those who had not; they suggested that therapeutic training provides staff with skills in containing emotion. Training staff to manage the emotional impact of the work, such as through distress tolerance and managing relational issues, may be more beneficial, for example, than training around descriptive and factual information on self-harm.

From this review, it is apparent that staff require a forum by which they are able to think about, process, and learn from the emotional impact of their work on themselves and on patients. Improving staff well-being through increasing reflection, self-awareness and emotion regulation could encourage a healthy foundation on which to build effective staff/patient 
interactions. This could be achieved through linking staff in acute hospital settings with staff trained in therapeutic approaches such as psychologists, who can facilitate reflective practice and provide formal and informal training around managing the relationship, distress tolerance, and emotional regulation skills. Although in busier environments the ability to engage with patients on a more meaningful level is limited, the ability to contain one's own emotion may protect against counterproductive impulse reactions. Managing the emotional impact of the work may be enough in itself to begin to change the way in which staff provide care to people who self-harm.

Facilitating changes in staff well-being and clinical skill requires management to encourage and prioritize time for staff development. Building staff development into preexisting times of increased staff numbers, such as hand-over periods, would allow for team members to be able to take part, without depriving the wards of staff. Promoting staff support and development as part of appraisals and continuing professional development may increase motivation for staff to attend.

The present meta-synthesis sought to explore the caregiving relationship with people who self-harm in hospital settings. Identifying the relational experiences of staff in wider settings, such as the community, may provide further understanding into interactions that may affect care and recovery. The review has highlighted processes that occur in the development and maintenance of unhelpful staff reactions which may inform further research into understanding the development of stigma in health care settings.

Limited research has been carried out on interventions improving the relationship between staff and patients around self-harm. An experimental research project could be undertaken intervening with staff around implementing ways of 'knowing yourself and knowing who's in front of you'. This may help identify the validity of the interpretation in whether improving the interaction could improve outcome, effectiveness, and sustainability. Additionally, an experimental project could be undertaken into the impact of introducing more support structures into PH environments.

\section{Conclusions}

The present review identified inhibitory and facilitative processes that may form part of hospital staff interactions with people who self-harm. The identified processes support previous research in the need to understand patients' relationships with staff to improve care.

The emotional impact on staff of working with people who self-harm can be significant. This review places an emphasis on increasing access to staff support to improve distress tolerance and develop staff awareness of their contribution to the relationship. Training programmes for staff could include understanding and managing the relational issues, developing an awareness of the self in relation to the patient, managing emotional responses, and using support systems and reflective groups. Developing the relationship is likely to improve experiences of care for both staff and patients.

\section{References}

Adshead, G. (1998). Psychiatric staff as attachment figures. Understanding management problems in psychiatric services in the light of attachment theory. The British Journal of 
Psychiatry, 172(1), 64-69. doi:10.1192/bjp.172.1.64

Artis, L., Smith, J., \& Scarff, J. (2012) Emergency department staff attitudes towards people who self-harm and the influences of norms on behaviour (Doctoral thesis). University of Exeter. Retrieved from https://ore.exeter.ac.uk/repository/bitstream/handle/10036/3718/ArtisL.pdf?sequence=4

Bowlby, J. (1973). Attachment and loss: Vol. 2. Separation: Anxiety and anger. New York, NY: Basic Books.

Byrne, G., \& Heyman, R. (1997). Understanding nurses' communication with patients in accident and emergency departments using a symbolic interactionist perspective. Journal of Advanced Nursing, 26(1), 93-100. doi:10.1046/j.1365-2648.1997.1997026093.x

Care Quality Commission (2014). Key findings for the national accident and emergency patient survey 2014. Retrieved from

http://www.cqc.org.uk/sites/default/files/20141201_accident_and_emergency_survey_2 014 key findings.pdf

Care Quality Commission (2015, May). National NHS patient survey programme: National results from the 2014 inpatient survey. Retrieved from http://www.cqc.org.uk/sites/default/files/201500519\%20NHS\%20Inpatient $\% 20$ Survey $\%$ 202014\%20National\%20summary\%20and\%20results\%20tables\%20FINAL.pdf

Chapman, A., Gratz, K., \& Brown, M. (2006). Solving the puzzle of deliberate self-harm: The experiential avoidance model. Behaviour Research and Therapy, 44(3), 371-394. doi:10.1016/j.brat.2005.03.005

Chapman, R., \& Martin, C. (2014). Perceptions of Australia emergency staff towards patients presenting with deliberate self-poisoning: A qualitative perspective. International Emergency Nursing, 22(3), 140-145. doi:10.1016/j.ienj.2014.03.002

Cole-King, A., \& Gilbert, P. (2011). Compassionate care: The theory and the reality. Journal of Holistic Healthcare, 8(3), 29-37.

Crittenden, P. (1999). Danger and development: The organisation of self-protective strategies. In J. I. Vondra \& D. Barnett (Eds.), Atypical attachment in infancy and early childhood among children at developmental risk (pp. 145-171). Oxford, UK: Blackwell.

Department of Health (2003). Improving the patient experience in accident and emergency departments. London, UK: Author.

Eastwick, Z., \& Grant, A. (2004). Emotional rescue: Deliberate self-harmers and A\&E departments. Mental Health Practice, 7(9), 12-15. doi:10.7748/mhp2004.06.7.9.12.c1809

Gratz, K. (2003). Risk factors for and functions of deliberate self-harm: An empirical and conceptual review. Clinical Psychology: Science and Practice, 10(2), 195-205. doi:10.1093/clipsy.bpg022

Hadfield, J., Brown, D., Pembroke, L., \& Hayward, M. (2009). Analysis of accident and emergency doctors' responses to treating people who self-harm. Qualitative Health Research, 19(6), 755- 765. doi:10.1177/1049732309334473

Health and Social Care Information Centre (2013, November). Mental health bulletin: Annual report from MHMDS returns - England 2012/2013. Retrieved from

http://www.hscic.gov.uk/catalogue/PUB12745/mhb-1213-ann-rep.pdf

Health and Social Care Information Centre (2014, January). Hospital episode statistics: Accident and emergency attendances in England 2012-13. Retrieved from 
http://www.hscic.gov.uk/catalogue/PUB13464/acci-emer-atte-eng-2012-2013-rep.pdf

Hopkins, C. (2002). "But what about the really ill, poorly people?" An ethnographic study into what it means to nurses on medical admissions units to have people who have harmed themselves as their patients. Journal of Psychiatric and Mental Health Nursing, 9(2), 147154. doi:10.1046/ j.1365-2850.2002.00473.x

Huband, N., \& Tantam, D. (2000). Attitudes to self-injury within a group of mental health staff. British Journal of Medical Psychology, 73(4), 495-504. doi:10.1348/000711200160688

Karman, P., Kool, N., Poslawsky, I. E.,\& van Meijel, B. (2015). Nurses' attitudes towards selfharm: A literature review. Journal of Psychiatric and Mental Health Nursing, 22(1), 6575. doi:10.1111/jpm.12171

Kelley, J., Kraft-Todd, G., Schapira, L., Kossowsky, J.,\&Riess, H. (2014). The influence of the patient clinician relationship on healthcare outcomes: A systematic review and metaanalysis of randomised control trials. PLoS ONE, 9(4), e94207. 4. doi:10.1371/journal.pone.0094207

Kings Fund (2014, October). Growing concerns about staff morale as NHS performance slips. Retrieved from http://www.kingsfund.org.uk/press/press-releases/growing-concernaboutstaff-morale-nhs-performance-slips

Kings Fund (2015, March). What's going on in A\&E? The key questions answered. Retrieved from http://www.kingsfund.org.uk/projects/urgent-emergency-care/urgent-andemergency-caremythbusters

Lilley, R., Owens, D., Horrocks, J., House, A., Noble, R., Bergen, H., . . Kapur, N. (2008). Hospital care and repetition following self-harm: Multicentre comparison of selfpoisoning and self-injury. The British Journal of Psychiatry, 192(6), 440-445. doi:10.1192/bjp.bp.107.043380

Linehan, M. (1993). Cognitive-behavioral treatment of borderline personality disorder. New York, NY: Guilford Press.

Martin, C., \& Chapman, R. (2014). A mixed method study to determine the attitude of Australian emergency health professionals towards patients who present with deliberate self- poisoning. International Emergency Nursing, 22(2), 98-104. doi:10.1016/j.ienj.2013.09.002

Mattson, A.,\&Binder, P. (2012). A qualitative exploration of how health care workers in an inpatient setting in Norway experience working with patients who self-injure. Nordic Psychology, 64(4), 272-290. doi:10.1080/19012276.2012.768034

McAllister, M., Creedy, D., Moyle, W., \& Farrugia, C. (2002). Nurses' attitudes towards clients who self-harm. Journal of Advanced Nursing, 40(5), 578-586. doi:10.1046/j.13652648.2002.02412.x

National Institute of Health and Clinical Excellence (2004). Clinical guidance 16. Self-Harm: The short-term physical and psychological management and secondary prevention of selfharm in primary and secondary care. Leicester, UK: BPS; London, UK: RCPsych.

National Institute of Health Research (2008). Attitudes towards and satisfaction with services among deliberate self-harm patients: A systematic review of the literature. Retrieved from http://www.netscc.ac.uk/hsdr/files/project/SDO_RS_08-1617-116_V01.pdf

Noblit, G., \& Hare, R. (1989). Meta-ethnography: Synthesising qualitative studies. Newbury Park, CA: Sage. 
O'Donovan, A. (2007). Pragmatism rules: The intervention and prevention strategies used by psychiatric nurses working with non-suicidal self-harming individuals. Journal of Psychiatric and Mental Health Nursing, 14(1), 64-71. doi:10.1111/j.13652850.2007.01044.X

O’Donovan, _A., \& Gijbels, H. (2006). Understanding psychiatric nursing care with nonsuicidal selfharming patients in acute psychiatric admission units: The views of psychiatric nurses. Archives of Psychiatric Nursing, 20(4), 186-192. doi:10.1016/j.apnu.2005.12.007

Paterson, B., Dubouloz, C.-J., Chervrier, J., Ashe, B., King, J., \& Moldoveanu, M. (2009). Conducting qualitative metasynthesis research: Insights from a metasynthesis project. International Journal of Qualitative Methods, 8(3), 22-33.

Paterson, B. L., Thorne, S. E., Canam, C.,\&Jillings, C. (Eds.) (2001). Meta-study of qualitative health research: A practical guide to meta-analysis and meta-synthesis. London, UK: Sage Publications Inc.

Rees, N., Rapport, F., Thomas, G., John, A., \& Snooks, H. (2014). Perceptions of paramedic and emergency care workers of those who self-harm: A systematic review of the quantitative literature. Journal of Psychosomatic Research, 77(6), 449-456. doi:10.1016/j.jpsychores.2014.09.006

Sandelowski, M., \& Barroso, J. (2003). Classifying the findings in qualitative studies. Qualitative Health Research, 13(7), 905-923. doi:10.1177/1049732303253488

Saunders, K. E., Hawton, K., Fortune, S.,\&Farrell, S. (2012). Attitudes and knowledge of clinical staff regarding people who self-harm: A systematic review. Journal of Affective Disorders, 139(3), 205-216. doi:10.1016/j.jad.2011.08.024

Senarathna, L., Adams, J., De Silva, D., Buckley, N. A., \& Dawson, A. H. (2008). Personal and professional challenges in the management of deliberate self-poisoning patients in rural Sri Lanka: A qualitative study of rural hospital doctors' experiences and perceptions. BMC Public Health, 8(373), 1-7. doi:10.1186/1471-2458-8-373

Sheard, T., Evans, J., Cash, D., Hicks, J., King, A., Morgan, N., . . Ryle, A. (2000). CATderived one to three session intervention for repeated deliberate self-harm: A description of the model and initial experience of trainee psychiatrists in using it. British Journal of Medical Psychology, 73(2), 179-196. doi:10.1348/000711200160417

Smith, J. R., \& Louis, W. R. (2009). Group norms and the attitude-behaviour relationship. Social and Personality Psychology Compass, 3(1), 19-35. doi:10.1111/j.17519004.2008.00161.X

Taylor, T., Hawton, K., Fortune, S., \& Kapur, N. (2009). Attitudes towards clinical services among people who self-harm: Systematic review. The British Journal of Psychiatry, 194(2), 104-110. doi:10.1192/bjp.bp.107.046425

Taylor, R., Marshall, T., Mann, A., \& Goldberg, D. (2012). Insecure attachment and frequent attendance in primary care: A longitudinal cohort study of medically unexplained symptom presentations in ten UK general practices. Psychological Medicine, 42(4), 855864. doi:10.1017/S0033291711001589

Tofthagen, R., Talseth, A. G., \& Fagerstr€om, L. (2014). Mental health nurses' experiences of caring for patients suffering from self-harm. Nursing Research and Practice, 2014, 1-10. doi:10.1155/2014/905741 
Tong, A., Sainsbury, P., \& Craig, J. (2007). Consolidated criteria for reporting qualitative research (COREQ): A 32-item checklist for interviews and focus groups. International Journal for Quality in Health Care, 19(6), 349-357. doi:10.1093/intqhe/mzm042

Vedsted, P., Fink, P., Sorensen, H.,\&Olesen, F. (2004). Physical, mental and social factors associated with frequent attendance in Danish general practice. A population-based crosssectional study. Social Science \& Medicine, 59(4), 813-823. doi:10.1016/j.socscimed.2003.11.027

Walsh, D., \& Down, S. (2005). Meta-synthesis method for qualitative research: A literature review. Journal of Advanced Nursing, 50(2), 204-211. doi:10.1111/j.13652648.2005.03380.x

Wilstrand, C., Lindgren, B. M., Gilje, F., \& Olofsson, B. (2007). Being burdened and balancing boundaries: Aqualitative study of nurses' experiences caring for patients whoself-harm. Journal of Psychiatric and Mental Health Nursing, 14(1), 72-78. doi:10.1111/j.13652850.2007. 01045.x 